\section{Colour atlas of lacrimal surgery}

Olver (Editor) $£ 85.00$

ISBN 0723434869

Eye (2003) 17, 682. doi:10.1038/ sj.eye. 6700434

This is a really excellent book and fills a gap in the market. It covers all areas of how to investigate and deal with a patient with epiphora from examination and investigation through to surgical management.

Dacrocystorhinostomy is extensively explained from its historical perspective to its current application including both external and endoscopic approaches. The advantages and disadvantages of both approaches are well laid out with useful tips to prevent problems. There are also chapters on paediatric lacrimal problems, canalicular surgery, including the repair of canalicular tears, and also a good practical chapter on lid surgery. Newer, less widely accepted techniques like balloon catheter dilation and nasolacrimal duct stenting are also touched upon. The best thing about the book is the extensive array of high-quality photographs and line drawings illustrating not only pathology but also operative technique in a simple and easy-to-follow manner. It is particularly well endowed with endoscopic images highlighting the benefit of the endoscope to the lacrimal surgeon. There are also CT scans and photos of prosections and the bony architecture to help the reader understand the anatomy.

The book is set out in a very sympathetic and easy-to-follow manner, ideal for dipping into as well as for more extensive reading, and at 200 pages long it is not too big to fit in a briefcase. It is very practical and I particularly liked the surgical 'tips' and the 'practice points'. The instrumentation required is listed or illustrated, laser settings are given, the stages required are clearly explained, and there is advice on postoperative management. Of particular benefit also are the scoring systems for quantifying epiphora, thus helping surgeons to more objectively document the results of their interventions. It does not provide a comprehensive list of all possible lacrimal pathology and its management, but it does succinctly cover the majority of conditions seen in a lacrimal clinic and it is well referenced to allow further reading around the subject. For me, the only main omission was how to tackle failed or re-do surgery.

I really like this book and feel it will become a bible for aspiring and existing lacrimal surgeons. It would certainly be of great benefit to all departments where patients with watering eyes are assessed.

Z Currie Consultant Ophthalmic Surgeon Department of Ophthalmology Royal Hallamshire Hospital Sheffield, UK

E-mail: zanna.currie@freeserve.co.uk 